Referencia para citar este artículo: Figueroa-Grenett, C. (2018). La acción política de niños, niñas y jóvenes en Chile: cuerpos, performatividad y producción de subjetividad. Revista Latinoamericana de Ciencias Sociales, Niñez y Juventud, 16(1), 199-212. doi:10.11600/1692715x.16111

\title{
La acción política de niños, niñas y jóvenes en Chile: cuerpos, performatividad y producción de subjetividad*
}

\author{
CLAUDIO FIGUEROA-GRENETT** \\ Académico Colaborador Universidad Alberto Hurtado, Chile.
}

Artículo recibido en marzo 21 de 2017; artículo aceptado en junio 2 de 2017 (Eds.)

- Resumen (analítico): En este artículo exploro las formas de acción política del Movimiento Estudiantil en Chile, especificamente las marchas y performances realizadas durante el año 2011. Empleo la perspectiva metodológica de la performance, que conecta el aparecer situado y contingente del cuerpo y la cuestión política como toma de posición en el espacio público. Los resultados destacan el uso intensivo del cuerpo y la incorporación de elementos festivos y lúdicos, lo que marca una diferencia con cierta institucionalización de la acción política y los ciclos de protesta que anteceden en Chile. Concluyo que las acciones políticas de los niños, niñas y jóvenes anudan placer y acción política, reconvierten las energías corporales, suspenden la lógica de enfrentamiento con la policía e inventan una ciudadanía en acto.

Palabras clave: niños, jóvenes, participación, movimiento social, ciudadanía, psicología política (Tesauro de Ciencias Sociales de la Unesco).

Palabras clave autor: acción política, performances, cuerpos, subjetividad.

\section{Political action of children and young people in Chile: bodies, performativity and production of subjectivity}

- Abstract (analytical): This article explores the forms of political action undertaken by the Student Movement in Chile, specifically the marches and performances that occurred during 2011. The methodological perspective of performances is used, which connects the situated and contingent appearance of the body and a political stance as a position in public space. The results highlight the intensive use of the body and the incorporation of festive and playful elements, which is distinct from the institutionalization of political action and the previous cycles of protest that occurred in Chile. The author concludes that the political actions of children and young people combine pleasure and political action to reconvert corporal energies, suspend the logic of confrontation with the police and invent a form of citizenship through action.

Key words: Children, young people, participation, social movements, citizenship, political psychology (Unesco Social Sciences Thesaurus).

Author's key words: political action, performances, bodies, subjectivity.

\footnotetext{
Este artículo corto hace parte del proyecto Morfologías del descontento social en chile 2011-2012, una aproximación interdisciplinaria, y se inscribe en la iniciativa Centro de Estudios de Conflicto y Cohesión Social (Coes), financiada por el Fondo de Investigación en Áreas Prioritarias (Conicyt/Fondap 15130009). El proyecto se inició el 1 de junio del 2014 y actualmente se encuentra en proceso de finalización. En este artículo presento algunos de los resultados de la investigación realizada. El área de conocimiento del presente artículo es otras ciencias sociales, mientras que la subárea corresponde a interdisciplinaria.

** Psicólogo U-Arcis, Magíster en Ciencias Sociales Universidad de Chile, Académico Colaborador en la Facultad de Psicología Universidad Alberto Hurtado. Orcid: 0000-0002-3746-4090. Correo electrónico: psclaudiofigueroa@gmail.com
} 


\section{A ação política de crianças e jovens no Chile: corpos, performatividade e produção de subjetividade}

- Resumo (analítico): o artigo explora as formas de ação política do Movimento Estudantil no Chile, especificamente as marchas e os desempenhos realizados em 2011. A perspectiva metodológica dos desempenhos é utilizada, que conecta a aparência situada e contingente do corpo e a questão política como uma posição no espaço público. Os resultados destacam o uso intensivo do corpo e a incorporação de elementos festivos e brincalhões, o que faz diferença com alguma institucionalização da ação política e os ciclos de protesto que precedem no Chile. Conclui-se que as ações políticas de meninos, meninas e jovens unem prazer e ação política, reconfortam as energias corporais, suspendem a lógica do confronto com a polícia e inventam a cidadania no ato.

Palavras-chave: crianças, jovens, participação, movimento social, cidadania, psicologia política (Thesaurus de Ciências Sociais da Unesco).

Palavras-chave do autor: ação política, performances, corpos, subjetividade.

-1. Introducción. -2. Método. -3. Perspectivas sobre movimientos sociales. -4. Hallazgos en las formas de acción política. -5. Producción de subjetividad y ciudadanía. -6. Conclusión. Lista de referencias.

\section{Introducción}

A partir del año 2011 se ha hablado de un nuevo ciclo de protestas y de la emergencia de fuerzas contra-hegemónicas frente el capitalismo global, unidas por el intento de recuperar los espacios públicos clausurados por el totalitarismo y cedidos a los mercados (Roitman-Rosenmann, 2012). Las manifestaciones sobresalieron por un carácter eminentemente espacial, en donde un recurso importante para la expresión de los ciudadanos y ciudadanas descontentos fueron las calles y las plazas recuperadas y convertidas en "fortines de ciudadanía" (Roitman-Rosenmann, 2011).

Los actos de ciudadanía que ocuparon el espacio público también tuvieron lugar en Chile, en lo que metafóricamente se llamó la "rebelión del coro" (Garcés, 2012). La escena teatral con los protagonistas comenzó a ser interrumpida por múltiples actores no invitados a aparecer. Las manifestaciones de Punta Arenas por el aumento del precio del gas, las marchas ecologistas en rechazo del proyecto eléctrico Hidro Aysén y las minorías sexuales exigiendo derechos, dan cuenta del contexto en el que el Movimiento Estudiantil comienza a adquirir visibilidad en el espacio público.

El Movimiento Estudiantil puede ser comprendido como la expresión corporalizada de un proceso de fortalecimiento de estudiantes de secundaria y de universidad, es decir, de los niños, niñas y jóvenes que pertenecen a esos espacios de socialización ${ }^{1}$. Este proceso de potenciación de aquellos considerados "menores de edad" por el sistema de dominación adultocéntrico, tuvo como punto de articulación durante el 2011 la denuncia por "falta de equidad en la educación", el reclamo de "educación de calidad para todos" y la propuesta de "educación pública, gratuita y de calidad para todos, sin lucro" (Unicef, 2014).

La presentación de la Ley de Calidad y Equidad en la Educación de enero del 2011, en el gobierno del presidente Sebastián Piñera, significaba el fortalecimiento de la municipalización, de modo opuesto a la exigencia social por una educación estatal, gratuita y de calidad, que se venía gestando durante el periodo (Banda \& Navea, 2013). La distancia entre la exigencia social y las reformas ofrecidas, abrieron un conflicto que

$1 \quad$ Si bien el presente análisis se concentra en acciones políticas del año 2011, existe una serie de eventos que favorecen la contextualización del periodo, sobre todo aquellos situados en el tramo 2005-2006. En el año 2005, los estudiantes secundarios entregaron un petitorio nacional que proponía una educación de calidad, laica y democrática. A partir de éste, en el año 2016, miles de estudiantes se hicieron parte de lo que se ha llamado la "Revolución Pingüina", en un cuestionamiento directo a la Ley Orgánica Constitucional de Enseñanza, que establecía el lucro en la educación y eximía al Estado de la responsabilidad de educación. En este contexto, se realizaron movilizaciones, tomas, paros y un "giro creativo-corporal" en la formas de acción política (prácticas paródicas, intervención de danza, flashmobs, entre otras). 
se fue materializando en los aparecimientos que caracterizaron a los niños, niñas y jóvenes descontentos: por un lado, las tomas de establecimientos y paros, y por otro, las marchas festivas y performances.

Las acciones políticas de los niños, niñas y jóvenes que disputaron el espacio público y la democratización del campo de visibilidad, se caracterizaron por el uso intensivo del cuerpo y la integración de elementos festivos y lúdicos, lo que muestra diferencias con cierta "institucionalización de la acción política" y con los ciclos de protesta que anteceden en Chile ${ }^{3}$. En este contexto, el presente artículo busca explorar las acciones políticas de los niños, niñas y jóvenes, destacando el modo singular de performar el cuerpo en el espacio público y el proceso de producción de subjetividad asociado a la experiencia de participación en marchas y performances.

\section{Método}

El presente artículo es fruto de una investigación de carácter interdisciplinario, desarrollada por un equipo de trabajo

$2 \quad$ Al respecto, cabe considerar el "cartel latinoamericano" como influencia de países socialistas y la psicodelia de los años 60 (Banda \& Navea, 2013), el muralismo de brigada que instala mensajes de protesta en las calles de la ciudad (Páez-Sandoval, 2015) y también las acciones convencionales y no convencionales asociadas al proceso electoral, las peticiones, las manifestaciones tradicionales, la desobediencia civil, las acciones violentas hacia la propiedad y las personas, que se encuentran clasificadas en diversas tipologías de la acción política (Muller, 1992; Sabucedo \& Arce, 1991; Tausch et al., 2011).

3 En Chile, la acción ciudadana-popular contra la dictadura se movió principalmente en dos planos, a saber: (1) como lucha comunitaria para la supervivencia y (2) como protesta y desafío rebelde contra el sistema dictatorial (Salazar, 2013). Sobre este punto, cabe destacar las jornadas de protesta nacional que estallaron durante cinco años consecutivos entre 1983-1987, que obligaron a la dictadura a negociar. Las convocatorias se hicieron a través de paredes pintadas y panfletos, las protestas se caracterizaron por su masividad, ocupando avenidas céntricas de la ciudad, que convergieron con paros en las empresas y escuelas, además de barricadas y enfrentamientos. En lo que respecta al periodo post-dictadura, el grueso de la ciudanía demoró en reaccionar y tomar una posición crítica sobre lo que habría ocurrido durante la transición democrática. Solo recientemente, con "el pingüinazo" del 2005-2006 y el movimiento estudiantil en el año 2011, se hizo posible establecer un nuevo ciclo de protestas representada por los niños, niñas y jóvenes, estudiantes de enseñanza básica, media y universitaria. Si bien no es posible eludir la existencia de similitudes con ciclos anteriores producto de aprendizajes del "movimiento ciudadano-popular", el presente trabajo supone la hipótesis — susceptible de revisión - de una diferencia en las formas de acción política, asociada a la incorporación de elementos festivos y lúdicos. conformado por investigadores e investigadoras pertenecientes a disciplinas como la filosofía, el teatro, la literatura, la sociología y la psicología. Esta investigación se situó desde el enfoque cualitativo (Corbetta, 2007; Ruiz-Olabuenaga, 1996) y la perspectiva metodológica de la performance.

Taylor (2003) propone que la performance, en un nivel, es el objeto/proceso de análisis de los Estudios de la Performance, y en otro, es una metodología que permite la aproximación a los fenómenos. De esta manera, es posible diferenciar entre una afirmación ontológica algo es o no es performance - y la posibilidad de utilizar el concepto como lente metodológico para analizar y comprender diversos fenómenos.

El concepto clave fue el de performatividad, que comprende una dimensión de la acción humana que relaciona: (a) la emergencia contingente y el acontecer corporizado con una dimensión estética en tanto aparecer; (b) lo histórico-cultural en tanto aparecer situado; y (c) la cuestión política en tanto intervención o toma de posición en el espacio público. Adicionalmente incorporé diversos insumos provenientes de los estudios sobre movimientos sociales, sociología del cuerpo y filosofía política contemporánea, proveyendo de nociones coherentes al carácter contingente y corporizado de lo social.

Apliqué el estudio de caso (Neiman \& Quarante, 2006; Stake, 2007) como herramienta de investigación que indaga una experiencia limitada pero significativa, favoreciendo profundidad en el abordaje. Sobre la base de diversos insumos conceptuales, analicé observaciones de material audiovisual y de campo. El procedimiento de análisis consistió en reconocer la producción de subjetividad generada en las relaciones entre los individuos participantes de las actividades, con el propósito de establecer recorridos posibles de significación.

\section{Perspectivas sobre movimientos sociales}

a) Movimiento social y cogito.

La manera tradicional de concebir los movimientos sociales ve en el incremento de agravios y tensiones sociales la causa 
de su nacimiento, al mismo tiempo que los movimientos sociales son representados como fenómenos excepcionales, irracionales y transitorios (Craig-Jenkins, 1994). De este modo se ha conformado una mirada conservadora que articula la diferencia entre las actuaciones institucionales, siempre racionales o adecuadas, y por otra parte las del movimiento, fuertemente caóticas o desmedidas ${ }^{4}$.

Desde el punto de vista de las reorientaciones teóricas de la década del 70, los movimientos sociales comienzan a ser concebidos como portadores de una racionalidad que les es inherente. Entre las teorías inscritas en esta perspectiva, es importante destacar la de movilización de recursos (McCarthy, 1999), las estructuras de oportunidades políticas (McAdam, 1999; Tarrow, 1997) y de marcos cognitivos (Chihu-Amparán, 2006; Snow \& Benford, 2006), en las que predominó la idea de una organización orientada por un sujeto portador de racionalidad, generando una suerte de ontologización de los movimientos sociales.

En el caso de estas teorías, el estudio sobre movimientos sociales exige atender ciertos aspectos específicos: evaluación racional de las oportunidades políticas, siempre en términos de costos y beneficios; gestión e inversión de recursos para la consecución de objetivos; e interpretación estratégica del mundo con el propósito de asegurar la unidad funcional. Este punto de arranque analítico, que pone como centro al cogito - sujeto autónomo y soberano- 5 , invisibiliza la potencia de una multiplicidad de prácticas que son irreductibles

4 La comprensión expuesta imprime dicotomías tales como orden/ revuelta, anomía/norma y razón/sin razón que encuentran figuras predilectas en la turba, en el marginal descarriado o en el enfermo anómico, lógicamente próximas a las imágenes del niño o niña, del sujeto delincuente o del individuo loco en los discursos del biopoder (Fernández-de Rota, 2008). Esto implica asumir como única posibilidad el fortalecimiento del orden por medio de la disciplina y el control de masas potencialmente peligrosas.

5 El binarismo irracional/racional, que es expresado, por un lado, en las perspectivas tradicionales sobre movimientos sociales $\mathrm{y}$, por otro, en las que parten de un sujeto racional y autónomo, expresa una dicotomía, pero no tanto un antagonismo de miradas. En el corte cartesiano entre el sujeto de la enunciación y el sujeto del enunciado, el "yo existo" siempre remite al cogito, que es un sujeto previo y sustraído de toda duda metodológica, el cual, en su autonomía, porta una capacidad racional inherente que permite la emancipación humana. Es aquí el lugar desde el cual se escinde una dimensión racional y su contrario, por lo que, una y la otra, son parte de un mismo plano epistemológico fundado por el cogito. a la noción de un sujeto racional y autosuficiente que establece acciones sobre la base de una intencionalidad.

Tomando en cuenta lo anterior, el riesgo de la perspectiva expuesta radica en reducir la "cuestión política" a la incidencia institucional y valorar únicamente los aspectos epidérmicos de los movimientos sociales, como son las estructuras de oportunidades, la movilización de recursos y los marcos cognitivos para la generación de adherencia. De esta manera se establece una equivalencia de sentido entre "la política" como ámbito de toma de decisiones, autoridades y estructuras institucionales para la regulación del conflicto, y lo político como insistencia ontológica de la conflictividad (Mouffe, 1999).

Los enfoques centrados en la estructura de oportunidades políticas y el proceso político han realizado una lectura de los movimientos en las que se reduce la complejidad y heterogeneidad de los mismos a su relación con el sistema político institucionalizado siguiendo, en términos generales, las directrices de la teoría de la acción racional y la teoría de los marcos cognitivos (Mendiola, 2000, p. 88).

Sobre la base de estas consideraciones que advierten el riesgo de perspectivas que identifican los movimientos sociales con un sujeto racional y autónomo, cabe indicar que la comprensión de aspectos que exceden la "cuestión institucional" requiere de un tratamiento distinto de aquel que puede otorgar cierta "analítica del sujeto" para el estudio de los movimientos sociales. La construcción de un tratamiento de otra índole se encuentra presente en diversas claves de interpretación que relevan la capacidad instituyente de los movimientos sociales y el estatuto performativo del cuerpo en la producción de realidades sociales emergentes.

b) Movimiento social y performatividad

Avanzar en una comprensión que reconozca la capacidad instituyente de las acciones y discursos de los movimientos sociales, significa sobre todo prestar atención a la producción actual — aquí y ahora — de las orientaciones que 
invocan, pues la potencia de los movimientos sociales radica en que "no exigen, sino que ofrecen [...] por medio de su propia existencia [...] otros modos de definir el significado de la acción individual y colectiva" (Melucci, 1999, p. 103). Este punto de vista valora la pluralidad de formas de habitar y conformar el campo social, las articulaciones inéditas que se generan, el desplazamiento de fronteras y la introducción de prácticas disruptivas.

(...) prácticas situadas en entornos en los que interactúan — son pues prácticas internas a un contexto de dominaciónpero en los que cortocircuitan las prácticas de reproducción ordinarias, las boicotean, sustituyéndolas en parte, construyendo un tejido social alternativo, generando un espacio en el que pueden ocurrir otras cosas (Galcerán-Huget, 2009, pp. 69-70).

Desde este punto de vista, las acciones políticas de los movimientos sociales son concebidas como aparecimientos/ acontecimientos contingentes, corporizados y situados en el espacio público (Taylor, 2003). La producción de subjetividad se origina por medio de acciones y procedimientos en una situación específica, por lo que la colectividad transitoria que supone un movimiento social alude al acto entre-muchos que performativamente instituye -aquí y ahora- modos de existencia (Fernández, 2011). Las acciones y procedimientos que producen subjetividad en situación, enseñan cierto modo de hacer propio del movimiento social que puede habilitar un espacio-tiempo alternativo y la dimensión de $l o$ político.

Por este motivo los movimientos sociales no necesariamente reafirman una identidad preexistente; más bien producen estados de pasaje o transversiones a través de los modos de hacer que despliegan, lo que va re-configurando los límites instituidos en el encuentro como experimentación con los otros ${ }^{6}$. La capacidad

$6 \quad$ El ser singular plural es un ser que es esencialmente un ser en común: "el ser en común significa que los seres singulares no son, no se presentan, no aparecen más que en la medida en que com-parecen, en que están expuestos, presentados u ofrecidos unos a otros" (Nancy, 2001, p. 110). Una de las características más importantes de la singularidad es que está siempre expuesta al afuera, comparece en el parto del entre, en donde el entre-nosotros - tú y yo- no demuestra una fórmula de la yuxtaposición de los individuos, sino más bien el valor de la pura exposición, infinita de producir una versión distinta de nosotros mismos hace de la experimentación con otros un devenir incesante, abierto e indefinido, y precisamente por ello, los movimientos sociales instituyen - imaginan, inventan - un bordado de prácticas y discursos que producen subjetividades en situación, al unísono que reivindican un derecho que es negado.

(...) dimensión subjetiva que se produce en acto, que produce sus potencias en su accionar; es decir, pensar básicamente en un campo de inmanencia y no trascendencia, singular y no universal. No se trata aquí de definir qué es la subjetividad sino de pensar cómo se instituyen las dimensiones subjetivas en las situaciones colectivas que indagamos (Fernández, 2007, p. 281).

El desplazamiento de los fundamentos identitarios o representacionales en la tarea de comprender la acción política de los niños, niñas y jóvenes, permite una aproximación en términos de experienciarios (Fernández, 2011), es decir, de los procesos de producción de subjetividad en devenir permanente, siempre dinámicos y flexibles, desde los cuales son refiguradas performativamente las modalidades de pensar, sentir y actuar ${ }^{7}$, en consonancia con las perspectivas pos-fundacionales que subrayan el carácter contingente y conflictivo de lo social (Marchart, 2009).

Frente a la actual modulación que constituye cuerpos "marcados y hablados por los signos, las palabras, las imágenes (logos de la empresa)" (Lazzarato, 2006, pp. 106107), performados en cierta recursividad de los hábitos que los hace girar en torno al trabajo y al consumo administrado, es importante mencionar que los cuerpos también pueden

el padecimiento respecto a los semejantes, el encuentro como experimentación con y sobre el otro: "padezco la, o su, alteridad, y la, su, alteración, que $<<$ en mí mismo $>>$ pone mi singularidad fuera de mí, y que la finaliza infinitamente" (Nancy, 2000, p. 64).

7 Desde esta perspectiva no será operativa cierta concepción moderna de subjetividad que tiene como punto de partida el corte cartesiano entre un sujeto de la enunciación y un sujeto del enunciado, caracterizado por el "yo existo" que remite al cogito, como sujeto previo sustraído de toda duda metódica. En este sentido, la producción de subjetividad revela un proceso siempre singular y en situación, que integra la sujeción y "los restos" no sujetados o las resistencias, pero en cualquier caso no una suerte de interioridad psicológica que antecede a lo social y se prefigura como dada. 
performarse, devenir otros de sí, exceder la norma y dibujar la posibilidad de suspender las incitaciones del poder que los han configurado (Butler, 2004, 2012). En este sentido, se trata de cierta "ambivalencia del cuerpo", que indica la existencia sincrónica de los componentes de resistencia y los de subordinación.

Por ello es posible señalar que el cuerpo "es portador de subjetividad política en tanto aloja prácticas de dominación, pero también de liberación [...] es intervenido, usado y expuesto continuamente en el proceso de la militancia política" (Duque-Monsalve, Patiño-Gaviria, Muñoz-Gaviria, Villa-Holguín, \& CardonaEstrada, 2016, p. 146). Las acciones políticas que despliegan los cuerpos son siempre expresión y proceso productor de subjetividades, nos habla de su realización viva o de su materialización en un campo de conflictos determinado. En efecto, el cuerpo es el lugar y el medio para performar la subjetividad y hacer visible una reivindicación de derechos, lo cual siempre exige una puesta en escena y la transgresión del propio cuerpo.

En este marco de consideraciones, se hace necesario pensar el modo de aparecer y comparecer de los cuerpos como una experimentación radical con los otros, que en algunos casos permite profanar las modalidades instituidas de existencia. A pesar de la fugacidad y ausencia de "golpes de trascendencia" en las acciones políticas, la creación de "pactos performativos" puede habilitar otros modos de sentir, pensar y actuar en una situación determinada, insinuando procesos singulares de producción de subjetividad que ofrecen, imaginan, inventan y no solo demandan a la sociedad o al Estado.

\section{Hallazgos en las formas de acción política}

a) Las marchas de los niños, niñas $y$ jóvenes.

El adultocentrismo es un sistema de dominación —articulado por procesos económicos y políticos propios del capitalismo - que "delimita accesos y clausuras a ciertos bienes, a partir de una concepción de tareas de desarrollo que a cada clase de edad le corresponderían [...] que incide en la calidad de sus despliegues" (Duarte-Quapper, 2012, p. 111). La organización adultocéntrica asienta capacidades y posibilidades de controlar acciones en roles considerados inherentes al mundo adulto, mientras ubica a los niños, niñas y jóvenes — también a las mujeres, a los individuos adultos mayores y a las diversidades sexuales - en roles subordinados.

Para la re-producción del estilo de organización adultocéntrico se han desplegado mecanismos en el plano simbólico y cultural, como son las significaciones sociales adultocéntricas $^{8}$, que instituyen un tratamiento del espacio público en tanto determinan visibilidades e invisibilidades, un afuera $\mathrm{y}$ un adentro, reconocimientos y exclusiones, al tiempo que performan el despliegue de los cuerpos, incidiendo en los trayectos, detenciones, repliegues y exhibiciones. Esto se relaciona con una división o reparto de los tiempos, los lugares y las ocupaciones para cada clase de edad, que va configurando recursivamente la manera en que "lo común" es visto y entendido.

El hecho de que la ciudad haya sido

8 Las significaciones sociales conforman imaginarios (Castoriadis, 2010) a través de los cuales los colectivos — grupos, instituciones, sociedad - se constituyen como tales, definiendo las relaciones sociales-materiales, delimitando las formas contractuales e instituyendo los universos de sentido que establecen las líneas de demarcación entre lícito e ilícito, permitido y prohibido, bello y feo, relevante y accesorio, etc. (Fernández, 2007). Los mecanismos culturales y simbólicos del adultocentrismo operan de manera implícita a través del conjunto de significaciones sociales $\mathrm{y}$, de este modo, instituyen un tratamiento particular para la infancia - y la juventud - caracterizado por la subalternización de este grupo social. Desde diversas investigaciones (Bustelo, 2011; Duarte-Quapper, 2012; Gaitán, 2006; Rodríguez-Pascual, 2007) se desprende la existencia de un tratamiento instituido hacia los "menores de edad", que se encuentra sostenido en presupuestos biológico-evolutivos y se despliega a través de mecanismos simbólicos. Al respecto, es posible señalar: (a) la universalización de la infancia, que consiste en la definición de etapas asociadas al traspaso de crisis de crecimiento, a la evaluación cognitiva y al desarrollo psicosocial, de modo tal que niños y niñas son inscritos sobre la base de un a-priori teleológico que se manifiesta en la delimitación de transcursos universales del ser humano conducentes a un estado civilizado de existencia, que coincide con determinado ideal de vida adulta; (b) la idealización de la infancia implica concebir a niños y niñas como portadores de una esencia caracterizada por la inocencia, la indefensión, la pureza, la ternura y la bondad, desde lo cual se desprende un tratamiento compasivo desde el mundo adulto, a través de prácticas de beneficencia de carácter paternal y, por lo tanto, asimétricas; (c) la estigmatización de la infancia opera en aquellos niños y niñas que no logran ser conducidos correctamente en los espacios de socialización o que son desprotegidos por el mundo adulto, creando un modo de comprensión residual respecto de cierta infancia normal, que involucra el tutelaje y/o corrección por parte de las instituciones. 
construida por y para el mundo adulto (Tonucci, 2012) — que consume y ocupa los roles de control-, muestra que el espacio público está regulado, dividido o repartido, y en consecuencia, no puede sino ser concebido como un lugar político y estratégico para quienes desean reivindicar un derecho. En estrecha relación con el problema del espacio público regulado $\mathrm{y}$ del cuerpo performado, o como una suerte de consecuencia, se ubica una política que enlaza con una estética; se trata de una política de la puesta en escena y de la transgresión del cuerpo, que en este caso supondría la interrupción del trasfondo simbólico-cultural adultocéntrico.

Las marchas que enredaron diversos elementos —zancos, batucadas, comparsas, marionetas, malabarismo, cuerpos intervenidos, freestyle de rap, entre otras-, significaron el desplazamiento de los niños, niñas y jóvenes desde las periferias, escuelas y universidades al centro de la ciudad. Este movimiento desde las instituciones de socialización hacia el centro como lugar de decisión política, advierte una verdadera dislocación del reparto o división de ocupaciones, tiempos y espacios propios del adultocentrismo, toda vez que la marcha como acto ritual involucra aparecer políticamente, hacerse inteligible y visible a los ojos de los otros, lo que supone una alteración de las normas que regulan la vida pública (UrzúaMartínez, 2015).

La irrupción de los cuerpos de los niños, niñas y jóvenes fue una operación conflictiva respecto del modo en que "lo común" es visto y entendido, pues significó el dibujo en la superficie de otro sujeto político y la suspensión de las significaciones sociales que identifican a "los más jóvenes" como objetos de socialización. Desde esta lectura, la política de la puesta en escena y la transgresión del cuerpo desnaturaliza las significaciones sociales adultocéntricas, en todo momento que arremete contra la incapacidad, dependencia e irracionalidad atribuida a los "más jóvenes". Frente al ejercicio adultocéntrico que vacía de politicidad a la niñez y a la juventud, la colectividad transitoria generada por el Movimiento Estudiantil interrumpe el espacio de circulación instituido y, en un mismo gesto, visibiliza la reivindicación de un derecho por parte de los niños, niñas y jóvenes.

¡Circulen! No hay nada que mirar. La policía dice que no hay nada que mirar en una calzada, nada que hacer salvo circular. Dice que el espacio de circulación solo es el espacio de circulación. La política consiste en transformar este espacio de circulación en un espacio de manifestación de un sujeto: el pueblo, los trabajadores, los ciudadanos. Consiste en refigurar el espacio, lo que hay que hacer, que ver y que nombrar (Rancière, 2006, pp. 71-72).

Visto desde este punto de vista, es relevante señalar que toda "acción política [...] se despliega en un escenario público, ante un público, los ojos y oídos de otros individuos con quienes se establecen lazos/separaciones a partir de acciones y palabras" (Guindi, 2016, p. 51). Por este motivo, la ciudad no puede ser limitada por la dimensión física de una ciudadestado o por su existencia administrativa. Por el contrario, la experiencia de la ciudad se configura sobre la base de las relaciones que performativamente instituyen exclusiones y reconocimientos, invisibilidades y visibilidades, en definitiva, de la situación de ser-con-otros.

La re-figuración del espacio de circulación se relaciona con un modo singular de aparecercomparecer de los cuerpos, que puede caracterizarse por la presencia de una exposición eminentemente festiva en el encuentro con otros. Sin el interés de profundizar en el hecho de que la marcha como acción política se sitúe fuera o dentro del sistema institucional, es necesario relevar que la incorporación de una dimensión festiva adquiere una importancia crucial al momento de comprender las formas de acción política de los niños, niñas y jóvenes. Es la dimensión festiva de la acción política la que insinúa una potencia creativa distinta ni más, ni menos - respecto de los ciclos de protesta que anteceden en Chile.

La presencia de batucadas, comparsas, danzas, cuerpos intervenidos, marionetas y diversas expresiones artístico-culturales que fueron desplegadas y conformaron las marchas durante el año 2011, mostraron una forma de aparecer-comparecer de los cuerpos en la que los 
niños, niñas y jóvenes se enredaron en un modo transitorio de socialidad festiva. Sobre este punto, es interesante señalar que la festividad se caracteriza por una efervescencia opuesta a lo cotidiano y a todas sus prohibiciones, actualizando una fuerza desbordante y creadora que suspende el orden del mundo y expande la incertidumbre por todas partes (Caillois, 2006).

La dimensión festiva presente en la marcha supone la desestabilización de lo instituido en una sociedad, y la emergencia de un espacio-tiempo intersticial ${ }^{9}$, en cuyo intervalo incierto respecto de un antes y un después los cuerpos realizan un gasto rebelde de las energías corporales, preformándose a sí mismos en dicha economía corporal. En este sentido, la dimensión festiva arroja los cuerpos a una política de la transgresión de sí mismos y de suspensión de su despliegue cotidianoinstituido, al tiempo que interpela las formas habituales de acción política.

La cultura de la fiesta actual recobra, en la multiplicidad de sus manifestaciones, un denominador común: la insólita capacidad para congelar el tiempo, para evaporar la vivencia característica de temporalidad gobernante en la racionalizada cotidianidad. Dicho de otro modo, en este espacio tiempo/festivo se diluye - se escamotea - la reglamentada y encorsetadora experiencia del tiempo ordinario, provocando la experiencia de estar ubicado fuera del tiempo real (Carretero-Pasín, 2006, pp. 448-449).

Si entendemos que el "tiempo real" coincide con la retirada del placer a favor del trabajo, de la disciplina, del consumo administrado y del ahorro burgués, la re-figuración del cuerpo a través de la dimensión festiva constituye un paréntesis respecto del "tiempo real". En efecto, la expresión festiva presenta una economía desbordada, inoperante o improductiva de las energías corporales, a contrapelo del gasto utilitario o productivo propio del capitalismo (Scribano, 2009b). Los cuerpos de los niños,

\footnotetext{
9 Cierto estado liminal o intersticial apunta a una suerte de suspensión de la identidad cultural de un sujeto durante los ritos de pasaje; se trata de un espacio de suspensión de la condición que le antecede sin que por ello se reposicione una demora, intervalo o espacio transitivo (Turner, 1988).
}

niñas y jóvenes que asumen un gasto de energías corporales sin finalidad, manifiestan una verdadera "reconversión de las energías sociales y corporales que permiten abrir, expandir y multiplicar las potencialidades de los sujetos y colectivos" (Scribano, 2009a, p. 149).

\section{b) Las performances callejeras.}

Durante el año 2011 el Movimiento Estudiantil desarrolló diversas formas de acción política, entre las cuales se pueden destacar los paros, las marchas y las tomas de establecimientos educacionales. De manera paralela, se realizaron performances en diversos puntos del país, que sobresalieron por la creatividad suscitada y la aceptación de una parte importante de la ciudadanía ${ }^{10}$. Para la lectura de las performances realizadas por los niños, niñas y jóvenes se han considerado fundamentalmente dos experiencias: la "Maratón por la Educación" y la "Playa Itinerante".

\section{- Maratón por la Educación:}

El 13 de junio del 2011, un estudiante de teatro de la Universidad de Chile inició la "Maratón por la Educación" individual que, en el marco de las discusiones de asamblea, atrajo la participación de 30 personas y más de 4300 durante todas las horas de maratón, en un intento de rodear de manera permanente el Palacio de La Moneda. Bajo la consiga "1800 horas por la educación", que hacía referencia a los 1800 millones de dólares que costaría financiar la educación gratuita y de calidad en Chile, los cuerpos corrieron un total de kilómetros suficientes para dar la vuelta por la Línea del Ecuador, en una suerte de protesta ininterrumpida que tuvo una duración de 75 días.

10 En el documental Chile se moviliza: Movimiento estudiantil 2011, presentado por el canal de televisión La Red durante el año 2013, Camila Vallejos y Francisco Figueroa destacan el carácter simbólico que tuvieron las movilizaciones durante el año 2011, el cual logró encantar y transmitir de la mejor manera las demandas del movimiento estudiantil a la sociedad chilena por medio de otras formas de hacer política.

11 Más bien centrado en la problemática intergeneracional de dos historias de vida que confluyen en La maratón por la educación, el documental El Vals de los Inútiles, dirigido por Edison Cájas y estrenado durante el año 2013, constituye un registro de las manifestaciones estudiantiles del año 2011. 
En esta acción se constató la insistencia de los cuerpos, mensajes escritos en la piel y banderas que problematizaron el espacio público, configurando un dispositivo de resistencia con formas de convocatoria, autogestión solidaria, alimentos para las personas adherentes, seguridad y mensajes de protesta.

\section{- La Playa Itinerante:}

"La Playa Itinerante" surgió en junio del 2011, en el contexto del rechazo por parte del movimiento estudiantil a la propuesta del Gobierno que no respondía a la demanda de "educación pública, gratuita y de calidad para todos, sin lucro". En este contexto, el Ministro de Educación Joaquín Lavín anticipó las vacaciones de invierno, con el propósito de "evitar seguir perdiendo clases" producto de las tomas de los establecimientos educacionales. Frente a esto, los niños, niñas y jóvenes movilizados generaron una Playa Itinerante en diversos puntos de Santiago, iniciativa que surgió desde el Colegio Carmela Carbajal ubicado en Providencia, extendiéndose a Plaza de Armas y a las afueras de la casa central de la Universidad de Chile. Los cuerpos se ubicaron en los espacios públicos con trajes de baño, utilizando bronceadores, quitasoles y gorras, jugando tenis de playa y cantando canciones veraniegas, simulando de este modo acciones propias de los balnearios, pero en el centro de la ciudad. El procedimiento consistió en una aceptación paródica de la medida del gobierno, encarnando la exigencia del poder pero con un desfase que la hizo absurda. El aparecercomparecer de los cuerpos desplegó un proceso material de significación a través de una crítica corporizada, desactivando paródicamente la orden de la autoridad.

La "Maratón por la Educación" y la "Playa Itinerante" se caracterizan por tres elementos clave:elprimeroserelacionaconlaincorporación de una dimensión lúdica en la acción política; el segundo, con la habilitación de un espaciotiempo de participación placentera; y el tercero y último, tiene que ver con el distanciamiento respecto de la "lógica de enfrentamiento" con la policía. Los tres elementos mencionados atraviesan la apropiación del espacio público y el uso intensivo del cuerpo, además de marcar una diferencia con las formas de acción política convencional y no convencional, según una clasificación divulgada que integra desde prácticas de voto hasta conductas violentas (Barnes \& Kaase, 1979).

La dimensión lúdica presente en las performances callejeras realizadas por los niños, niñas y jóvenes ilumina la comprensión de las formas de acción política en el marco del Movimiento Estudiantil durante el 2011. Se ha mencionado que el juego logra establecer un campo de ambigüedad entre "lo real" y "lo falso", y precisamente de este modo, puede generar una realidad emergente que desestabiliza la cotidianidad instituida (Kanngieser, 2007). Se trata de un tipo de juego complejo, en el cual la premisa "esto es un juego" y "esto es la realidad" deja de tener eficacia, instalándose así una suerte de "metáfora en serio" en donde la acción lúdica significa y ofrece algo que tiene implicancias en la realidad.

Al incorporar el juego y al [Sic] arte como elementos que permiten una capacidad de creación e innovación ausente en otras esferas de la vida social (...) la socialidad privilegia el aspecto instituyente de las relaciones sociales y restaura, de manera estructural, la eficacia simbólica en los pequeños grupos (Urteaga-Castro, 2012, p. 30).

En los casos de la "Maratón por la Educación" y la "Playa Itinerante", los cuerpos establecen relaciones que hacen surgir realidades emergentes. Si bien las acciones no son espontáneas, al ser realizadas suscitan eventos no controlados: los niños, niñas y jóvenes diseñan las performances en espacios de socialización como las escuelas y las universidades, y al momento de deponerlas en práctica, otros cuerpos se hacen parte de las actividades. Desde este punto de vista, la presencia de lo lúdico en las variaciones corporales muestra una práctica inmersa en un litigio "socio-político urbano donde la intervención activa de una corporalidad flexible y dinámica constituye una performance revolucionaria estética-política" (Scribano, 2016, p. 20), toda vez que contagia el placer de la participación social y posibilita otro uso de las energías corporales. 
En este marco de consideraciones, la dimensión lúdica puede ser comprendida como un tipo de accionar profundamente profano o negligente que restituye el libre uso y significado de las cosas, a contrapelo de los usos instituidos o utilitarios (Agamben, 2005). En efecto, las performances callejeras de los niños, niñas y jóvenes restituyen el uso de los cuerpos y de los objetos a través de operaciones creativas que parodian las exigencias del poder. Por otro lado, cabe destacar que la potencia del juego no solo radica en el placer generado y en el uso profano de lo existente, sino también en el hecho de que la acción política logra trabar la "lógica de enfrentamiento" con la policía.

La activación del enfrentamiento entre "policías de choque" y "encapuchados" o blackbloc, es la fórmula a través de la cual el Estado criminaliza e integra los movimientos sociales, toda vez que fragmentos de las marchas ejercen una identificación con las imágenes que dispone el Estado para representar, gestionar y controlar el conflicto. En las performances callejeras no es posible detectar una relación de enfrentamiento, y más bien se observa un modo de aparecer-comparecer de los cuerpos que, haciendo confusa la diferencia entre acción política y juego, suspende la violencia policial.

Desde este punto de vista, las performances callejeras generarían una situación liminal o intersticial (Turner, 1988) que impide que las identidades instituidas propias de la presentación estatal del conflicto se polaricen. La ambigüedad entre acción política y juego paraliza la posibilidad de criminalizar el movimiento social, en todo momento en que la policía no encuentra soporte o estímulo alguno para activar la "lógica de enfrentamiento". El intervalo que traba la radicalización de identidades instituidas advierte la potencia de la "máquina (de guerra) lúdica": fuga de la representación estatal e invención de un accionar que abre un posible aqui y ahora para la conquista de derechos.

La máquina de guerra alude, paradójicamente, a una máquina que no tiene por objetivo la guerra, sino más bien trazar una línea de fuga creativa que pueda desertar del aparato de Estado. Esto se traduce en la evitación de toda integración coercitiva

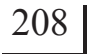

asociada a una política de las oposiciones, o de un orden estructurado dualmente, como sucede en la "lógica de enfrentamiento" con la policía ${ }^{12}$. Desde esta lectura, el juego y su despliegue aparentemente inofensivo puede producir una realidad emergente que, de algún modo u otro, tensiona lo establecido y aventura nuevas formas efectivas de acción política.

(...) la máquina de guerra no tiene de por sí la guerra como objeto; su objeto es más bien trazar una línea de fuga creativa, componer el espacio liso y desplazar a las personas en ese espacio (...) La combinación de fuga e invención, de deserción del aparato de Estado y movimiento instituyente, en definitiva la invención de una fuga instituyente, es la cualidad específica de la máquina de guerra (Raunig, 2008, p. 57).

La "invención de una fuga instituyente" tiene lugar en el modo en que aparecencomparecen los cuerpos que sobresalen por el uso lúdico de la materialidad y el placer en la acción política. En este sentido, la potencialidad de las performances callejeras consiste en generar un sentido de colectividad en situación, motivando la participación y limitando la criminalización del movimiento social. Es la realidad emergente generada $-y$ la suspensión de lo instituido - lo que permite de algún modo $\mathrm{u}$ otro visibilizar la reivindicación de derechos de los niños, niñas y jóvenes.

\section{Producción de subjetividad y ciudadanía}

El patrón de ciudadanía de las democracias occidentales tiende a universalizar la figura del hombre, adulto y racional, excluyendo a "grupos minoritarios" identificados con la irracionalidad, las pasiones y la dependencia (Young, 2000). Las marchas y las performances callejeras, en la medida en que surgen de

12 El aparato de Estado es un modelo. Se trata de oposiciones relativas pero como división de lo Uno - déspota/legislador, violento/ tranquilo, etcétera-, que funcionan emparejadas, alternativamente, componiendo una unidad soberana. El Estado procede Uno-Dos, que distribuye las distinciones binarias y forma un medio de interioridad. Este sería un modo de pensamiento habitual, en donde se presenta una racionalidad interna que articula las partes dentro de un todo, y en coherencia, busca representar, interiorizar y subordinar toda exterioridad para los propios objetivos (Deleuze \& Guattari, 2002). 
una dinámica del estar-juntos que incorpora elementos festivos y lúdicos en el uso de los cuerpos y en la apropiación del espacio público, interpelan la forma instituida de concebir la ciudadanía asociada "con un estatus otorgado por el Estado en el que queda fuera tanto la dimensión de la agencia de los individuos como la capacidad de estos de reivindicar y conquistar nuevos derechos" (Benedicto, 2016, p. 928).

El juego y lo festivo que atraviesan el modo de aparecer-comparecer de los cuerpos dan cuenta de un proceso singular de producción de subjetividad en situación. El experienciario generado por el accionar de los niños, niñas y jóvenes tiene la particularidad de re-convertir las energías corporales a través del gasto inoperante de estas, suspender la "lógica de enfrentamiento con la policía", y en un mismo movimiento, anudar placer y política en la tarea de reivindicar derechos. La realidad emergente que ofrece el Movimiento Estudiantil no solo se aleja de cierta "institucionalización de la acción política", sino que también se contrapone a la emblemática imagen moderna del sujeto adulto, serio, responsable y calculador.

Desde esta lectura, las acciones políticas analizadas visibilizan una figura distinta que se encuentra relacionada con el individuo "adolescente o infante eterno" (Maffesoli, 2009), caracterizada por la presencia de un barroquismo comportamental y el desborde de las energías corporales, en la que el quehacer lúdico $\mathrm{y}$ festivo surge como manifestación punzante y contraria a los valores modernos asociados al ser humano, racional y autónomo. A este respecto, no se trata de esencializar o naturalizar el accionar de los niños, niñas y jóvenes, sino de apreciar la singularidad del proceso de producción de subjetividad que desarrollan.

A pesar de los argumentos que insisten en el impacto de la desafección política en las acciones no convencionales (Mardones, 2014) o la importante discusión sobre su consistencia (Hatibovic-Díaz, F. \& Sandoval-Moya, 2015), el hecho de que la acción política lúdica y festiva forje performativamente una realidad emergente, exige sostener que los niños, niñas y jóvenes están lejos de distanciarse de la política.
Más exactamente, lo que se entrevé son "actos de ciudadanía que la hacen existir de forma material" (Balibar, 2013, p. 209), en donde el juego y lo festivo operan como condición de posibilidad de una ciudadanía que excede el estatuto formal o republicano.

En coherencia, el proceso de producción de subjetividad problematiza la ciudadanía concebida como logro, en la que los niños, las niñas, los jóvenes y las jóvenes son representados como ciudadanas y ciudadanos futuros o en desarrollo, sobre la base de un conjunto de expectativas construidas por el mundo adulto y el Estado. A contrapelo de la mirada adultocéntrica, el accionar de los niños, niñas y jóvenes hace de "la ciudadanía una invención permanente o una identificación que se debe construir y propiciar a pesar de que no se encuentra dada empíricamente" (FigueroaGrenett, 2016, p. 135), en la que los elementos lúdicos y festivos abren el desorden y re-figuran el placer del estar-juntos, en el mismo acto de reivindicar un derecho negado por la sociedad.

El acto de la extralimitación moral refuerza el vínculo ético pues, al permitir expresar lo imaginario, lo lúdico y las fantasías, la manifestación y la representación del desorden recupera todo lo que configura la validez del vivir en común. Al contrario de la moral económica, que funciona siempre con la vista puesta en el mañana - religioso y profano - y que en consecuencia administra con mesura sus haberes materiales y afectivos, el goce del presente se agota en el mismo acto" (Maffesoli, 1996, p. 25).

La potencia existente en los modos singulares de socialidad convoca a reconocer que los elementos festivos y lúdicos son en serio, en la medida que ofrecen una experiencia de aparecer-comparecer de los cuerpos que forja realidades emergentes. De esta manera, el componente instituyente de la acción que introduce una cuota de desorden en lo cotidiano es el que genera una ciudadanía de la niñez y la juventud en acto, imbricando placer y política en un modo de accionar que hace visible la reivindicación de derechos por parte de los niños, niñas y jóvenes. 


\section{Conclusión}

Las marchas y performances se caracterizan por el uso intensivo del cuerpo y la apropiación del espacio público por medio de elementos lúdicos y festivos. Esta experiencia de participación política muestra una potencia creativa diferente en comparación con las acciones políticas habituales, ya se trate de prácticas de voto, manifestaciones clásicas y ejercicio de la violencia. En este marco de consideraciones sobre la acción política de los niños, niñas y jóvenes en Chile, cabe destacar cuatro elementos clave que permiten comprender las experiencias:

(i) Anudamiento entre placer y acción política.

(ii) Reconversión inoperante de las energías corporales.

(iii) Suspensión de la "lógica de enfrentamiento" con la policía.

(iv) Invención de ciudadanía en acto.

Los elementos mencionados enseñan la singularidad del proceso de producción de subjetividad, en el que prevalece la experimentación colectiva y el placer que se agota en cada acto, en contraposición de la cultura ascética y utilitaria propia de los valores modernos. Para este análisis requerí de una aproximación que relevara la performatividad de los cuerpos - su aparecer corporizado, contingente, situado y políticodistanciándome de una analítica del sujeto que visibiliza únicamente las oportunidades políticas, los marcos cognitivos y la gestión de recursos para el análisis de la acción política.

\section{Lista de referencias}

Agamben, G. (2005). Profanaciones. Buenos Aires: Adriana Hidalgo.

Balibar, E. (2013). Ciudadanía. Buenos Aires: Adriana Hidalgo.

Banda, C., \& Navea, V. (2013). En Marcha. Ensayos sobre arte, violencia y cuerpo en la manifestación social. Santiago: Adrede.

Barnes, H., \& Kaase, M. (1979). Political action. Mass participation in five western democracies. Londres: Sage.
Benedicto, J. (2016). La ciudadanía juvenil: un enfoque basado en las experiencias vitales de los jóvenes. Revista Latinoamericana de Ciencias Sociales, Niñez y Juventud, 14(2), 925-938. doi:10.11600/169271 5x.14203210415

Bustelo, E. (2011). El recreo de la infancia: argumentos para otro comienzo. Buenos Aires: Siglo XXI.

Butler, J. (2004). Deshacer el género. Buenos Aires: Paidós.

Butler, J. (2012). Cuerpos que importan. Buenos Aires: Paidós.

Caillois, R. (2006). El hombre y lo sagrado. México, D. F.: Fondo de Cultura Económica.

Carretero-Pasín, E. (2006). Cultura festiva. Lo imaginario disloca lo cotidiano. Revista Imaginário, 12(14),439-456. doi:10.11606/ issn.1981-1616.v12i13p439-456

Castoriadis, C.(2010). Lainstitución imaginaria de la sociedad. Buenos Aires: Tusquets.

Chihu-Amparán, A. (2006). Introducción: construcción de marcos interpretativos. En A. Chihu-Amparán (Ed.), El análisis de los marcos en la sociología de los movimientos sociales. México, D. F.: Universidad Autónoma Metropolitana.

Corbetta, P. (2007). Metodologías de la investigación social. México, D. F.: McGraw-Hill.

Craig-Jenkins, J. (1994). La teoría de la movilización de recursos y el estudio de los movimientos sociales. En M. RevillaBlanco (Comp.) Movimientos sociales, acción e identidad. Madrid: Pablo Iglesias.

Deleuze, G., \& Guattari, F. (2002). Mil Mesetas. Valencia: Pre-Textos.

Duarte-Quapper, C. (2012). Sociedades adultocéntricas: sobre sus orígenes y reproducción. Última Década,(36), 99-125. doi:10.4067/S0718-22362012000100005

Duque-Monsalve, L., Patiño-Gaviria, C., Muñoz-Gaviria, D., Villa-Holguín, E., \& Cardona-Estrada, J. (2016). La subjetividad política en el contexto latinoamericano. Una revisión y una propuesta. Revista CES Psicología, 9(2), 128-151. doi:10.21615/ cesp.9.2.9 
Fernández,A. M. (2007). Las lógicas colectivas: imaginarios, cuerpos y multiplicidades. Buenos Aires: Biblos.

Fernández, A. M. (2011). Política y subjetividad: asambleas barriales $y$ fábricas recuperadas. Buenos Aires: Biblos.

Fernández-de Rota, I. A. (2008). Movimientos sociales. Una lectura a partir del postestructuralismo. Revista Athenea Digital, (14), 63-81. doi:10.5565/rev/ athenead/v0n14.487

Figueroa-Grenett, C. (2016). ¿Ciudadanía de la niñez? Hallazgos de investigación sobre el movimiento por una cultura de derechos de la niñez y adolescencia en Chile. Revista Última Década, (45), 118-139. doi:10.4067/S0718-22362016000200007

Gaitán, L. (2006). Sociología de la Infancia: nuevas perspectivas. Madrid: Síntesis.

Galcerán-Huget, M. (2009). Deseo y libertad. Madrid: Traficantes de Sueños.

Garcés, M. (2012). El despertar de la sociedad. Los movimientos sociales en América Latina y Chile. Santiago: LOM.

Guindi, B. (2016). Buenos aires, ciudad partida. Reflexiones en torno del espacio y la democracia. Revista Cuestión Urbana, (1), 49-66.

Hatibovic-Díaz, F., \& Sandoval-Moya, J.(2015). Una representación metafórica de la acción política de estudiantes universitarios en Chile. Revista Última Década, (42), 11-37. doi:10.13140/RG.2.1.1263.9844

Kanngieser, A. (2007). Gestos de resistencia cotidiana. Recuperado de: http://eipcp.net/ transversal/0307/kanngieser/es/print .

Lazzarato, M. (2006). Por una política menor. Madrid: Mapas.

Maffesoli, M. (1996). De la orgía. Una aproximación sociológica. Barcelona: Ariel.

Maffesoli, M. (2009). El reencantamiento del mundo. Buenos Aires: Dedalus.

Marchart, O. (2009). El pensamiento político postfundacional: la diferencia política en Nancy, Lefort, Badiou y Laclau. Buenos Aires: FCE.

Mardones, R. (2014). La encrucijada de la democracia chilena: una aproximación conceptual a la desafección política. Revista Papel Político, 19(1), 39-59. doi:10.11144/ Javeriana.PAPO19-1.edca

McAdam, D. (1999). Orígenes terminológicos, problemas actuales $\mathrm{y}$ futuras líneas de investigación. En D. McAdam, J. McCarthy, \& M. Zald (Eds.), Movimientos sociales: perspectivas comparadas (pp. 49-70). Madrid: Istmo.

McCarthy, J. (1999) Adoptar, adaptar e inventar límites y oportunidades. En D. McAdam, J. McCarthy, \& N. Zald (Eds.), Movimientos sociales: perspectivas comparadas. (pp. 205-220). Madrid: Istmo.

Melucci, A. (1999). Acción colectiva, vida cotidiana y democracia. México, D. F.: Colegio de México.

Mendiola, I. (2000). Movimientos sociales y trayectos sociológicos. Bilbao: Universidad del País Vasco.

Mouffe, Ch. (1999). El retorno de lo político. Buenos Aires: Paidós.

Muller, E. (1992). An explanatory model of differing types of participation. European Journal of Political Research, (10), 1-16. doi:10.1111/j.1475-6765.1982.tb00001.x

Nancy, J. L. (2000). La comunidad inoperante. Santiago: LOM.

Nancy, J. L. (2001). La comunidad desobrada. Madrid: Arena Libros.

Neiman, G., \& Quaranta, G. (2006). Los estudios de caso en la investigación sociológica. En I. Vasilachis-de Gialdino (Comp.), Estrategias de investigación cualitativa. Buenos Aires: Gedisa.

Páez-Sandoval, C. (2015). El proceso de trabajo de las brigadas muralistas de los $80^{\prime}$ : hacia contribución del concepto de "arte político" en Chile. Revista Arte, Cultura y Ciencias Sociales, (5), 1-15.

Rancière, J. (2006). Política, policía y democracia. Santiago: LOM.

Raunig, G. (2008). Mil máquinas. Madrid: Mapas.

Rodríguez-Pascual, I. (2007). Para una sociología de la infancia: aspectos teóricos y metodológicos. Madrid: CIS.

Roitman-Rosenmann, M. (2011). Los indignados: el retorno de la política. Recuperado de: http:// 
w w w. va n g u a r d i a . c o m . m x / losindignadoselretornodelapolitica1108798.html.

Roitman-Rosenmann, M. (2012). Los indignados. El rescate de la política. Madrid: Pensamiento Crítico.

Ruiz-Olabuenaga, J. I. (1996). Metodología de la investigación cualitativa. Bilbao: Universidad de Deusto.

Sabucedo, J. M., \& Arce, C. (1991). Types of political participation: A multidimentional analysis. European Journal of Political Research, 20(1), 93-102. doi:10.1111/j.1475-6765.1991.tb00257.x

Salazar, G. (2013). Movimientos Sociales en Chile: trayectoria histórica y proyección política. Santiago de Chile: Uqbar.

Scribano, A. (2009a). ¿Por qué una mirada sociológica de los cuerpos y las emociones? En C. Figari, \& A. Scribano (Comps.), Cuerpos, subjetividades y conflictos: hacia una sociología. Buenos Aires: Ciccus.

Scribano, A. (2009b). Sociología de la felicidad: el gasto festivo como práctica in-tersticial. Revista Yuyaykusun, (2), 173-190.

Scribano, A. (2016). Cuerpos, emociones y sociedad en Latinoamérica: una mirada desde nuestras propias prácticas. Revista Latinoamericana de Estudios sobre Cuerpos, Emociones y Sociedad, 8(20), 12-26.

Snow, D., \& Benford, R. (2006). Marcos maestros y ciclos de protesta. En A. ChihuAmparán(Ed.), El análisis de los marcos en la sociología de los movimientos sociales. México, D. F.: Universidad Autónoma Metropolitana.

Stake, R. (2007). Investigación con estudio de casos. Madrid: Morata.

Tarrow, S. (1997). El poder en movimiento. Los movimientos sociales, la acción colectiva y la política. Madrid: Alianza.

Tausch, N., Becker, J., Spears, R., Christ, O., Saab, R. Singh, P., \& Siddiqui, R. N. (2011). Explaining radical group behavior: Developing emotion and efficacy routes to normative and non-normative collective action. Journal of Personality and Social Psychology, 101(1), 129-148. doi:10.1037/ a0022728.
Taylor, D. (2003). The archive and the repertoire, performing cultural memory in the Americas. Durham, Londres: Duke University Press.

Tonucci, F. (2012). La ciudad de los niños. Buenos Aires: Losada.

Turner, V. (1988). El proceso ritual. Madrid: Taurus.

Unicef. (2014). La voz del Movimiento Estudiantil 2011. Educación pública, gratuita y de calidad. Santiago de Chile: Fondo de las Naciones Unidas para la Infancia.

Urteaga-Castro, M. (2012). De jóvenes contemporáneos: trendys, emprendedores y empresarios culturales. En N. GarcíaCanclini, F. Cruces, \& M. Urteaga-Castro (Eds.), Jóvenes, Cultura Urbanas y Redes Digitales. Madrid: Ariel.

Urzúa-Martínez, S. (2015). ¿Cómo marchan los jóvenes en el Chile postdictadura? Última Década, (42), 39-64. doi:10.4067/S071822362015000100003

Young, I. M. (2000). La justicia y la política de la diferencia. Madrid: Cátedra. 